\title{
Spillovers across European sovereign credit markets and role of surprise and uncertainty
}

\author{
Stelios Bekiros \\ European University Institute (EUI), Florence, Italy \\ Email: Stelios.Bekiros@eui.eu \\ Syed Jawad Hussain Shahzad \\ Montpellier Business School, Montpellier, France \\ South Ural State University, Chelyabinsk, Russian Federation \\ Email: j.syed@montpellier-bs.com \\ Chaker Aloui \\ College of Business Administration, Prince Sultan University, Riyadh, Saudi Arabia \\ Email:caloui@psu.edu.sa \\ Rania Jammazi \\ National School of Computer Science (ENSI), Tunis, Tunisia \\ Email: rania.jammazi@ensi-uma.tn
}

\begin{abstract}
We identify the network structure of spillovers and time-varying spillover intensities across European sovereign credit markets proposing a novel Copula-Granger causality based structural vector auto-regressive (SVAR) approach. Via the proposed framework, we examine the topological and timevarying spillover and contagion between thirteen European credit markets, which is found to be consistent with crisis events. The heterogeneity in directional impacts could be useful in revealing contagion effects across the credit markets. We also find that newly proposed surprise and uncertainty indexes by Scotti (2016), among other macro-economic variables, significantly explain the spillover dynamics.
\end{abstract}

JEL Classifications: G1; G15; C5

Keywords: Credit markets; Copula; Europe; Graph theory; Spillovers; Contagion 


\section{Introduction}

The literature related to the determinants and the connectedness of sovereign credit default swaps (SCDS) has been rising hastily since early 2000s, i.e., when they were viewed as the most liquid derivatives in the financial markets. The factors determining the SCDS spreads and the time varying contagion effects and spillovers of sovereign risk across countries/regions are the two foremost strands of the SCDS literature. Regarding the first strand of the literature, the main research question is to identify the domestic and global risk factor effects on the SCDS spreads. The related literature is extremely abundant (Longstaff et al., 2011; Kocsis and Monostori, 2016; Blommestein et al., 2016). However, these studies fail to reach comprehensive understanding of the identification of those effects. The obtained results are still inconclusive. The second strand of the SCDS literature is closely related to the contagion concept and spillovers among SCDS spreads, which also comprises our focal research issue. Specifically, the expanding sovereign debt crisis has been followed by a proliferation of the contagion and spillovers of SCDS across countries/regions. The identification of real contagion is equivocal. It could be the case that the CDS markets are weakly or strongly connected to other markets simply because of their common exposure to global risk factors or common regional volatility shocks, which result in a time varying interaction. Correspondingly, regional shocks may be transmitted in a non-linear fashion with substantial time-varying intensities. In this vein, empirical results in the literature are varying widely and are still inconclusive regarding contagion and spillovers. The published results are abundant and largely depend on the exact perception of the contagion concept, the datasets used, and the empirical methodologies. For instance, Kalbaska and Gatkowski (2012) investigate the SCDS co-movements for the PIIGS countries, France, Germany and UK for the period (2005-2010) using EWMA correlation and Granger causality tests. The authors provided 
strong evidence of contagion effects. SCDS markets in Ireland and Spain exhibit the strongest effect on the SCDS European market.

Furthermore, using a time-varying vector auto-regression, Calice et al. (2013) show substantial variations in the pattern of SCDS transmission effects between maturities and across countries. De Bruyckere et al. (2013) investigate the contagion effect between banks and SCDS in European countries during the sovereign debt crisis. They identify three main channels of contagion: the guarantee channel, the asset holding and the collateral channel. Atil et al. (2016) were also concerned with the SCDS contagion phenomenon during the European debt crisis. Using a copula-GARCH framework, they uncover strong connectedness over time and unveil a relative resilience to the Euro debt crisis. Alter and Beyer (2014) implement the Diebold and Yilmaz (hereafter, DY) (2011) framework to assess volatility spillovers among SCDS spreads over the period 2009-2012.. In a quite similar approach, Bostanci and Yilmaz (2015) implement the DY (2012) framework to assess the network structure of SCDS for 38 countries over the period 2009-2014. The authors reveal some conspicuous differences between the network structures of SCDS returns and volatilities. For the SCDS volatility networks, they show that regional clusters are formed among emerging market countries along with the developed-country cluster. Ait-Sahalia et al. (2014) derived closed-form formulae for SCDS in the Eurozone countries and estimate their model by matching theoretical prices to their empirical counterparts. The authors provide evidence of self-interaction and asymmetric cross-linkages.

Quite similar findings are found by Galariotis et al. (2016) who investigate the determinants of SCDS and their volatility spillovers for the Eurozone countries using Panel Vector Autoregressive modeling. They provide evidence of considerable increase of the SCDS spreads variance for some peripheral countries (Spain, Portugal, Italy Greece and Ireland) while the 
spreads' volatility is decreasing for some leading European economics including Germany and, France. Additionally, implementing the independent component analysis (hereafter, ICA), Fabozzi et al. (2016) analyze the most distinct factors determining the SCDS spreads in the Eurozone during the recent European sovereign crisis. Combining the ICA approach with a standard GARCH model, the authors point out that the time-varying correlations indicate the decoupling between low credit risk countries such as Germany and high credit risk countries such as Greece. Hassan et al. (2017) analyze the intra and inter SCDS associations for different emerging countries from Asia, Europe and Latin America using the conditional correlations and the principal component analysis. The authors show that SCDS in Asian emerging countries show substantial connectedness among themselves, while their counterparts in Europe and Latin America exhibit weaker links.

In our work, we adopt a different framework compared to previous studies; specifically, we perceive the SCDS markets in the Eurozone as integrated and dynamic systems and we investigate the time-varying connectedness among SCDS while at the same time assessing the effects of the Eurozone debt crisis and the 2008 Global financial crisis (hereafter, GFC). Explicitly, we consider the mechanism that maintains the Eurozone' countries SCDS market as a system and we analyze the effective connectivity between SCDS spreads. Doing so, we implement a Granger-originated causality network analysis namely the copula method by $\mathrm{Hu}$ and Liang (2014).

Broadly speaking, network analysis has been widely used to capture the interaction of agents in complex systems in different research areas including computer science, neuroscience, cellular networks. However, the implementation of such causal networks is still innovative in financial complex systems. For Instance, Billio et al. (2012) assess the connectivity of banks, hedge funds, 
and insurance firms stock returns using principal component analysis and Granger causality networks. They uncover that the selected sectoral returns are highly interlinked via a complex and time varying network relationships. Interestingly, only few methods were thus far proposed in the CDS literature to uncover the network structure of the CDS spreads across countries. For instance, Leon et al. (2014) use the correlation-into-distance mapping techniques and a minimal spanning tree-based correlation-filtering methodology to identify informational hierarchy for 38 countries. Lastly, Kitwiwattanachai (2015) propose a probabilistic graphical framework capturing the network structure of CDS spreads and estimates the conditional default probability and the expected loss. For SCDS connectivity, to the best of our knowledge, this is the first study to apply the conditional Granger causality based structural VAR spillovers to uncover the dynamic interactions among them.

Our findings make at least three main contributions to the SCDS empirical literature. In the first place, our copula-Granger causality approach points out substantial causal flow of SCDS spreads from one market to another European market. Specifically, Sweden is evidenced as an exogenous source of spillover and affects the UK, Austria, Denmark, Netherlands and Norway but does not receive inflows from the other markets. Contrariwise, Denmark is a prime receiver in contemporaneous time from other markets, followed by UK and Norway.

Secondly, based on the structural VAR, we follow the DY (2014) within a rolling window spillovers framework to gauge the spillovers intensities among the selected SCDS markets. In this vein, we uncover that spillover is the highest for Italy and France. Denmark is the highest spillover receiver while Sweden receives the lowest spillovers effects. Furthermore, we uncover that the overall spillover index (SOI) among the SCDS markets is relatively high (84.9\%). More importantly, we found that the credit markets spillovers strengthened during GFC and ESDC 
periods, with strong jumps with the start of the financial crisis and persisted higher during the crisis periods and significantly decrease post-ESDC period and remains lower towards the end of our sample period.

Thirdly, it is worthily noting that our paper distinguish itself from previous works in a particular point. Specifically, we investigate the determinants of aggregate and net volatility spillovers among the SCDS markets. Doing so, we considered several determinants including interest rates, the surprise and uncertainty indexes suggested by Scotti (2016), and the VIX index as a global risk aversion measure, the US real business cycle condition as developed by Aruoba et al. (2009) and the US dollar to Euro exchange rate. We presuppose that these macroeconomic global factors can be considered as the leading drivers of the causality connectedness between the European SCDS markets. We found that the US interest rates and the US exchange rate against the Euro are explaining a large part of the SCDS market volatility spillovers. Moreover, we uncover that the enhancements in the US business conditions shrinks the credit market spillovers while the G-10 economic surprise index has no significant effect. Conversely, a substantial positive effect of the news surprise index and uncertainty index for the Euro region has been evidenced.

This paper is organized as follows: the following section presents the methodological framework we apply to undertake our analysis. Section 3 explains the data set under investigation. In Section 4 we display and interpret our empirical results, whilst section 5 concludes.

\section{Methodology}

2.1. Copula Granger causality approach by Hu and Liang (2014) 
The notion of Granger causality is a measure of directional influences between two variables. Despite its wide use in many research fields, this approach was not well tailored for revealing the data stylized facts such as volatility patters or nonlinear relationships. Therefore, tractable Copula-based Granger causality was developed by Hu and Liang (2014) with no explicit model (non-parametric) to assess high order nonlinear causality.

Technically, if we define $\left\{X=x_{t}, Y=y_{t}\right\}$ as two stationary stochastic processes, the hypothesis of causality from $X$ to $Y(X \rightarrow Y)$ can be specified as follows:

$$
f\left(y_{t+1} \mid y_{t}^{n} x_{t}^{m}\right)=f\left(y_{t+1} \mid y_{t}^{n}\right)
$$

where $f$ represents the conditional probability density, and $x_{\varepsilon}^{m}=\left(x_{\tau}, m \ldots x_{t-m+1}\right)$ and $y_{t}^{n}=\left(y_{t}, \ldots, y_{t-n+1}\right)$ the historical information of $X$ and $Y$, respectively. If Eq. (1) is effective, the knowledge of $X$ does not improve the prediction of $Y$. It is worth noticing that the aforementioned hypothesis forms the basis of defining Transfer Entropy, which is a powerful measure of information transmission between joint processes (Schreiber, 2000). A measure of Granger causality in terms of log-likelihood ratios can be defined as follows:

$$
G C_{X \rightarrow Y}=E\left[\frac{\log \left(f\left(y_{t+1} \mid y_{t}^{n}, x_{t}^{m}\right)\right)}{f\left(y_{t+1} \mid y_{t}^{n}\right)}\right]
$$

where $E$ denotes the expectation operation over the sample space. The given definition does not require any specific model implementation; thus, it is flexible enough to reflect the causality without restrictions and provide a convenient means to statistical inference under a nonparametric framework (Hu and Liang 2014). Knowing that the reliable GC estimation for 
multivariate distributions is a cumbersome task, the copula approach affords a tractable mathematical construction because of its major role in keeping the dependence structure out of the full joint probability density, i.e. enabling to adequately converting the marginal distributions into more flexible multivariate distribution functions. As provided by Bouezmarni et al. (2012), the direct estimation of the GC through the copula density can only be performed in a limited dimension space, while estimates can be computationally complex when dealing with highlydimensional data. The approach of $\mathrm{Hu}$ and Liang (2014) enables to recursively model a high dimensional copula into a set of low dimensional ones, providing an easy-to-implement GC estimation. Hence, the causality measure can be written:

$$
G C_{X \rightarrow Y}=E\left[\frac{\log \left(f\left(y_{t+1} \mid y_{t}^{n}, x_{t}^{m}\right)\right)}{f\left(y_{t+1} \mid y_{t}^{n}\right)}\right]=E\left[\frac{\log \left(h\left(y_{t+1}, x_{t}^{m} \mid y_{t}^{n}\right)\right)}{f\left(y_{t+1} \mid y_{t}^{n}\right) \times g\left(x_{t}^{m} \mid y_{t}^{n}\right)}\right]
$$

where $h$ is the conditional joint density of $(X, Y)$, and $f$ and $g$ are the given marginal densities, respectively. The conditional joint density $h$ can be expressed on the basis of a copula density function:

$$
\boldsymbol{h}\left(y_{t+1}, x_{t}^{m} b_{t}^{n}\right)=f\left(y_{t+1} \mid y_{t}^{n}\right) \times g\left(x_{t}^{m} \mid y_{t}^{n}\right) \times c\left(u, v b y_{t}^{n}\right)
$$

where $u=F\left(y_{t+1} \mid y_{t}^{n}\right)$ and $v=G\left(x_{t}^{m} \mid y_{t}^{n}\right) . F$ and $G$ are the given conditional marginal distributions of $Y$ and $X$. If we substitute Eq. (4) in Eq. (3), the Granger causality is obtained via the following formula:

$$
\text { 【 } G C \mathbb{1}_{\downarrow}(X \rightarrow Y)=E\left[\log C\left(F\left(y_{\downarrow}(t+1) \mid y_{\downarrow} t^{\dagger} n\right), G\left(x_{1} t^{\dagger} m \mid y_{\downarrow} t^{\dagger} n\right)|| y_{\downarrow} t^{\dagger} n\right\rfloor\right]
$$


The copula Granger causality method of $\mathrm{Hu}$ and Liang (2014) involves the conjugation of empirical conditional copulas under the Bernstein approximation (Sancetta and Satchell, 2004). The estimations are based on the construction of a fully data-driven empirical copula encompassing a non-parametric approach, thus avoiding any misspecification related to the parametric methods. The copula is estimated directly from the pair-wised returns for each sectoral data samples based on rank statistics (Nelson, 2006). In doing so, if $\left[x_{k} \mid y_{k}\right\}_{\mathrm{k}}{ }^{\mathrm{N}}$ is the sample of size $N$ from continuous bivariate distributions, the empirical copula is obtained by:

$$
C\left(\frac{i}{N}, \frac{j}{N}\right)=\frac{\text { number of pairs }(x, y) \text { in the sample with } x \leq x_{(\mathbb{D}}, y \leq y_{(\mathbb{D}}}{N}
$$

$X_{(i)}$ and $Y_{(i)} 1 \leq \mathbf{1}, \mathrm{j} \leq N$ display the rank statistics of the data samples. To ensure the effectiveness of the empirical copula estimation, the Kernel method is applied firstly to fit the conditional marginal distributions of CDS and stock returns, and then the Kernel is plugged to the previously described empirical copula in order to obtain the empirical conditional copula density as presented in Eq. (5).

As mentioned above, the Bernstein approximation is used to guarantee an optimal estimation of the empirical copula as it reinforces the estimation process without imposing any weight outside its support (Hu and Liang, 2014) and avoids the spiky profile (exhibited by the empirical copula) that may arise given the limited data. For a 2-dimensional copula density $C$, the Bernstein approximation is given by:

$$
c_{B}\left(u_{1}, u_{2}\right)=\sum_{v_{1}}^{m_{1}} \sum_{v_{2}}^{m_{2}} c\left(\frac{v_{1}}{m_{1}} \cdot \frac{v_{2}}{m_{2}}\right) \boldsymbol{h}_{v_{1}, m_{1}}\left(u_{1}\right)_{h_{v_{2}, m_{2}}}\left(u_{2}\right)
$$


where $\boldsymbol{h}_{v_{j, m_{j}}}\left(u_{j}\right)=\left(\begin{array}{c}m_{j} \\ v_{j}\end{array}\right) u_{j}^{v_{j}}\left(1-u_{j}\right)^{m_{j-v_{j}}}$ and $m_{j}$ is the size of copula in the $j^{\text {th }}$ dimension. The final estimation step comprises retaining the log of the optimal estimation and sum over the entire sample. The full computing procedure can be summarized in five steps as provided by $\mathrm{Hu}$ and Liang (2014): a) extracting the past information from the individual stock and CDS returns, b) computing their pair-wised marginal distributions $F\left(y_{t+1} \mid y_{t}^{n}\right), G\left(x_{t}^{m} \mid y_{t}^{n}\right)$ by using the kernel method described above, c) estimating the empirical copula density by plotting the kernel method to the empirical copula estimation as in Eq. (6), d) optimizing the copula density estimation process through the Bernstein approach and finally e) obtaining the logarithm of the estimated copula to test the expected results over the whole sample. In order to assess the robustness of the Granger copula estimation method, we aim to test its statistical significance. We consider the re-sampling technique to generate a baseline null hypothesis-distribution and more precisely, a local bootstrap process is undertaken to obtain the final surrogate data. The validation algorithm is described by the following main steps: firstly, the bootstrap data $\left(y_{t}{ }^{n^{*}}\right)$ is drawn from the density function of $y_{t}{ }^{n}$, and then $y_{t+1}{ }^{*}$ and $x_{t}{ }^{m^{*}}$ are separately generated from their specific conditional marginal distribution conditional on $y_{t}^{n^{*}}$. Next, this allows to obtain the bootstrapped Granger causality from the drawn samples. The aforementioned three steps are repeated $M$ times (e.g 50 times) to obtain the distribution of the estimated GC, with the rank statistic employed to determine the $p$-values. Finally, the validation of the causality hypothesis is accepted if the $p$-value of the GC is lower than the significant $p$-value (e.g., 0.05).

\subsection{Spillover analysis using refined structural VAR}


We utilize a two-step procedure to examine the spillovers among daily European credit spread series where the findings of copula Granger causality approach, described above, are used as an input to define the SVAR. We start with the vector autoregressive model of Sims (1980) as:

$$
\Delta S C D S_{t}=\mu+\sum_{i=1}^{l} B_{i} \Delta S C D S_{t-i}+e_{t}
$$

where $\triangle S C D S_{t}$ is a vector of changes in sovereign CDS (SCDS) spreads of European markets and $\mathrm{B}$ is the matrix of dynamic coefficients, with no straightforward interpretation. For appropriate economic interpretations and summarizing the dynamic structure, Eq. (8) is rewritten as an infinite moving average process:

$$
\triangle S C D S_{t}=\sum_{i=0}^{\infty} A_{i} \varepsilon_{t-i}, \quad t=1,2, \ldots, T
$$

where the matrix $A_{\bar{L}}$ can intuitively be interpreted as the so-called impulse response. The error from the $H$-step-ahead forecast of $\triangle S C D S_{t}$ conditional on information available at $t-i$ is $\xi_{t, H}=\sum_{h=0}^{H-1} A_{h} \varepsilon_{t+H-h}$ with variance-covariance matrix $\operatorname{CoV}\left(\xi_{t, H}\right)=\sum_{h=0}^{H-1} A_{h} \sum_{h}^{x} A_{\text {where }} \sum_{\text {is }}^{\mathrm{g}}$ the variance-covariance matrix of the error term in Eq. (8).

Like DY (2014), our spillover analysis follows the familiar notion of forecast error variance decomposition. However, the underlying shocks are not assumed to have a recursive contemporaneous causal structure as economic theory seldom provides guide for recursive causal orderings, thus makes the imposed restrictions arbitrary. We overcome this problem using the causal relations detected through copula Granger causality approach. Specifically, we estimate 
the forecast error variance decomposition using the copula Granger causality based structural VAR to quantify spillover intensities and time variation. ${ }^{1}$

A matrix $\phi(H)=\left[\phi_{i j}([H)]\right]_{i, j=1, n N}$, is estimated whose entry denotes the shock contribution of variable $j$ in the forecast error variance of variable ${ }^{i}$. The (own) shocks contributions of the variable $^{i}$ are contained in the main diagonal elements and the (cross) contributions of the other variables $j$ to the forecast error variance of variable $i$ are presented through the off-diagonal elements.

Following DY (2014), the total connectedness measure is defined as follows:

$$
T S(H)=\frac{\Sigma_{i, j=1, i \neq j}^{N} \phi_{i j}(H)}{\sum_{i, j=1}^{N} \phi_{i j}(H)} \times 100=\frac{\sum_{i, j=1, i \neq j}^{N} \phi_{i j}(H)}{N} \times 100
$$

The above equation helps to identify the directional spillovers across all variables. Specifically, we also define two directional connectedness measures, named 'from others' and 'to others'. The directional spillover from all the other variables $j$ to variable $i$ (from others) is given by:

$$
D S_{i+j}(H)=\frac{\Sigma_{j=1, j=i}^{N} \phi_{i j}(H)}{\Sigma_{i, j=1}^{N} \phi_{i j}(H)} \times 100=\frac{\Sigma_{j=1, j=i}^{N} \phi_{i j}(H)}{N} \times 100
$$

Similarly, the directional spillover from variable $i$ to all other variables $j$ (to others) is defined as follows:

\footnotetext{
${ }^{1}$ It is important to note that the Diebold-Yilmaz method is based on the notion of forecast error variance decomposition within the generalized VAR framework proposed by Koop et al. (1996) and Pesaran and Shin (1998) and the results of variance decomposition do not hinge on the ordering of the variables. We however impose a structure based on the outcome of copula Granger causality approach and our results could therefore be sensitive to the variables' ordering. We are thankful to the anonymous referee for pointing about this aspect.
} 


$$
D S_{i \rightarrow j}(H)=\frac{\sum_{j=1, j \neq i}^{N} \phi_{j i}(H)}{\sum_{i, j=1}^{N} \phi_{j i}(H)} \times 100=\frac{\sum_{j=1, j \neq i}^{N} \phi_{j i}(H)}{N} \times 100
$$

The difference between Eq. (12) and Eq. (11) is defined as the net directional connectedness from variable $i$ to all other variables.

$$
N S_{i}(H)=D S_{i \rightarrow j}(H)-D S_{i+j}(H)
$$

Using this measure, a variable $i$ can be identified as a receiver $\left(N S_{i}(H)<0\right)$ or transmitter $\left(N S_{i}(H)>0\right)$ in the system. It provides a net contribution of each variable to the system. Finally, the net pairwise directional connectedness of variable $i$ with variable $j$ is expressed as follows:

$$
N P S_{i \rightarrow j}(H)=\left(\phi_{j i}\left(H^{\prime}\right)-\phi_{i j}\left(H^{\prime}\right)\right) \times 100
$$

\section{Data and preliminary analysis}

Our sample consists of 13 European credit markets that includes Eurozone markets, peripheral countries, and central European countries (Italy, Portugal, Spain, Austria, Belgium, France, Germany, Netherlands, Ireland, UK and Denmark) and two north Scandinavian countries (Norway and Sweden). The motivation behind our choice is to explore the causal links over the entirety of the European region, hence reveal the geographical partitions of causal links and spillovers between European credit markets. The dataset consists of daily closing values of the 5year sovereign CDS index spreads. The time period ranges from November 13, 2007 to October 6, 2015, totaling 2059 daily observations. The start of the sample is purely based on the 
availability of liquid data on SCDS indices, which is obtained from Thomson Reuters DataStream. Figure 1 displays the Box plots for European SCDS spreads for full sample, GFC sub-sample (from 15 September 2008 till 4 November 2009), Eurozone sovereign debt crises (ESDC) (from 5 November 2009 till 26 November 2012) and finally the post ESDC crises subsample (from 27 November 2012 till 6 October 2015). The SCDS spreads and their variations are highest during ESDC sub-sample. SCDS spreads of Portugal, Ireland, Italy and Spain are higher compared to other countries for all periods except GFC, where the picture is different during GFC sub-period as the differences between SCDS spreads are lower in terms of magnitude and variations.

\section{[Insert Figure 1 here]}

The correlation between the CDS spread markets is visualized by the Heat maps (see Fig. 2). The color scale shows low to high positive correlations in blue to red colors, respectively. The correlation amplitude is strong/weak as the color switches from red towards blue. From the four correlation matrices, the full sample period is characterized by the existence of no specific clustering of SCDS markets; however, the highest correlation is noted between Italy and Spain for full as well as three sub-samples. Specifically, in the GFC-crisis period the correlation matrix exhibits highly positive correlation given the dominance of the red and yellow color for the countries grouped as Italy, Portugal, Spain, Austria, Belgium, France, Netherlands and Ireland. Norway distinguishes herself from the others due to its low correlation with all other credit markets.

During the ESDC sub-sample, we distinguish Austria, Belgium, France, Germany and Netherlands as the largest group incorporating highest pair-wise correlations. In the post-ESDC 
period, although the overall picture is filled with blue color indicating very low correlations, the countries mentioned to have high correlation during ESDC period once again show marginally higher pair-wise relationship. These correlation metrics highlight a possibility of contagion effects during crisis episodes and that the relationship between European credit markets is dynamic.

\section{[Insert Figure 2 here]}

\section{Empirical results}

Based on the copula Granger causality approach, the resulting causal graph (using $1 \%$ significance level) is shown in Figure 3, where we can indentify the causal-flow of SCDS spreads from one to another European market. Sweden appears to be an exogenous source of spillover and affects the UK, Austria, Denmark, Netherlands and Norway but does not receive inflows from the other markets. On the other hand, Denmark is a prime receiver in contemporaneous time from other markets, followed by UK ans Norway.

\section{[Insert Figure 3 here]}

As identified in Figure 3 and based on copula-based causal network, we write in Eq. (15) the innovation correlation matrix. The order of credit markets is as follows: Italy, Portugal, Spain, Austria, Belgium, France, Germany, Netherlands, Ireland, UK, Denmark, Norway, Sweden. We

assign the diagonal elements as 1 , and the nondiagonal element (ijth) as a parameter $b_{i, j}$ when the shocks variable $j$ contemporaneously causes the variable $i$ and 0 otherwise. According to Fig. 3, for example, Italy (1st market in the matrix) affects Portugal (the 2nd variable), Spain (the 3rd 
variable), Belgium (the 5th variable), and Denmark (the 11th variable). Thus, we have four parameters $b_{2, \mathbf{1}}, b_{3, \mathbf{1}}, b_{5, \mathbf{1}}$, and $b_{11, \mathbf{1}}$ in the first column vector for credit market shocks.

1\&0\&0\&0\&0\& $b_{1,6} \& 0 \& 0 \& 0 \& 0 \& 0 \& 0 \& 0 @ b_{z, 1} \& 1 \& b_{z, 8} \& 0 \& 0 \& 0 \& 0 \& 0 \& 0 \& 0 \& 0 \& 0 \& 0 @ b_{z_{1}, 1} \& 0 \& 1 \& 08$

Based on the structural VAR identified in Eq. (15), we follow DY (2014) to quantify the important one market in a network relative to other markets, calculating the market wide full sample spillover intensities in Table 1. As shown, the 12-day-ahead spillover intensity to others is the highest of Italy and France i.e., the contribution to others is $272.9 \%$ and $143.3 \%$ respectively, much higher than other European credit markets. We can also see that Sweden receives lowest spillovers (6.3\%) from the other credit markets whereas Denmark is the highest (161.0\%) spillover receiver. The overall spillover index (SOI) among all European credit markets is $84.9 \%$.

\section{[Insert Table 1 here]}

\subsection{Rolling window spillover analysis and determinants}

Our preliminary correlation analysis has shown that the connectedness among European credit markets is subject to change overtime and especially during the crisis periods. Therefore, we explore time-varying spillover intensity and thus we construct spillover indices by recursively estimating the variance decompositions each day with an expanding sample. ${ }^{2}$

\footnotetext{
${ }^{2}$ Unlike the rolling sample spillovers used by DY (2014), the recursive estimates capture better the stock effect rather than the flow effect of spillovers. Furthermore, the recursive estimates are not sensitive to the window length.
} 
The aggregate spillover intensity using Eq. (10), by estimating the 12-step ahead spillover index of the European credit markets is plotted in Fig. 4. The credit markets spillovers intensified during GFC and ESDC periods, with clear jumps from the start of crisis and remained higher during the crisis periods and significantly decrease post-ESDC period and remains lower towards the end of our sample period.

\section{[Insert Figure 4 here]}

In Table 2, we report the summary statistics of the aggregate and net directional spillover indices for European credit markets estimated recursively for 12 days ahead horizon. The mean of the aggregate credit spillover index is $75.04 \%$ and it has a maximum value of $87.71 \%$ with a standard deviation of $10.59 \%$. The values of individual country's net directional spillover indicate that Spain, Italy, Belgium, France, Austria, and Netherlands are net spillover transmitters on average, in descending order for magnitude. The other markets are net receiver of spillovers where the spillover is highest to Norway from other markets. It is important to examine the stationarity due rising intensities of spillovers and therefore, we apply augmented Dickey and Fuller $(1979,1981)$ unit root tests with an intercept and a time trend. All p-values are smaller than $10 \%$, rejecting the null hypothesis of unit root in series, hence the spillover indices are regarded as stationary series.

Next, we examine the determinants of aggregate and net directional spillovers of the European credit markets. U.S. short rate (one-month treasury rate) and term spread defined as the difference between the 10-year and three-month Treasury yields are used as proxies for the interest rate movements. Theoretically, increase in interest rates raise the risk neutral drift of process describing firms' value and hence decreases the probability of firms' value falling below 
the default threshold thus leads to lower credit spreads. Additionally, the interest rates and CDS spreads relationship can also be motivated through the established link of yield curve with future real economic activity. Therefore, the periods of economic recession are generally associated with the low interest rates and those periods also witness more frequent corporate defaults. We also consider the VIX index which is the Chicago Board Options Exchange (CBOE) Volatility index. The index calculates the implied volatility of the S\&P 500 index options for the next 30 days. This index is also refereed as the fear indicator and can be interpreted as a global risk aversion measure. Higher the index level greater the fear and uncertainty in the stock markets, thus increasing the probability of defaults (higher CDS spreads).

The more frequently used macroeconomic variables of business cycle typically exist with available data only at monthly or quarterly frequencies. However, to track the real business conditions based on macroeconomic indicators, some daily indicators have been developed. The U.S. business conditions index developed by Aruoba et al. (2009) make use of macro-economic indicators such as quarterly real gross domestic product, monthly industrial production, manufacturing and trade sales payroll employment and personal income less transfer payments, and weekly initial jobless claims. Due to its usefulness in academic research, this index is classified as one of the top 50 economic indicators by the Wall Street Journal. The index takes the value of zero on average and thus increases (decreases) reflect improving (deteriorating) macroeconomic conditions. Other than the possible determinants of spillover that reflect the US or global macro-financial conditions, we also consider the daily macro surprise indices such as Citigroup's economic surprise index for the G10 and recently proposed news surprise and uncertainty indexes of Scotti (2016), for the euro area. A negative change in Citigroup's economic surprise index for the G10 indicates deterioration in the global macroeconomic 
climate. A positive (negative) value of news surprise index of Scotti (2016) indicates that economic releases in Europe have been, on balance, higher (lower) than consensus which means that the agents were ex-post more pessimistic (optimistic) about the economy. Notably, a positive value does not reflect a better economy rather it shows that the economic forecasts were overly pessimistic (Scotti, 2016). The uncertainty index for the euro area measures the uncertainty about the realized real activity conditions. A smaller (greater) value of uncertainty index indicates that agents have, on balance, been less (more) uncertain about the current state of the economy and thus the index is expected to rise during recessions when there are higher probabilities of default.

Finally, we use the U.S. dollar to euro exchange rate because Flood and Hodrick (1986) points that shocks in one economy might also be transmitted to another depending on the exchange rate regime. The financial market's conditions in one country could rapidly transmit to others through portfolio flows that includes the so-called "carry trade". ${ }^{3}$ The data of these determinants is from August 19, 2008 until October 6, 2015, totaling 1859 daily observations and is obtained through Bloomberg.

Table 3 reports the daily correlation matrix of aggregate spillover index and the regression variables. The key points of correlations of the 12-day-ahead aggregate spillover index and the measures of macroeconomic and financial risks are as follows. Consistent with expectations, the aggregate spillover index decreases with the improvements in business conditions (ADS) and rises with the increase in other measures of increasing uncertainty, at the $1 \%$ significance level.

\footnotetext{
${ }^{3}$ The term carry trade implies borrowing a low-yield asset from one market and buying a hig-yield asset from another market to earn the interest rate differential and the expected foreign currency appreciation.
} 
However, the correlation of spillover index with the U.S. interest rate (Short), the Citigroup's economic surprise index for the G10 ( $\triangle \mathrm{CESG} 10)$ and currency factor $(\triangle \mathrm{FX})$ is insignificant.

\section{[Insert Table $2 \& 3$ here]}

Finally, we regress the aggregate and net directional spillover indices on our selected set of macroeconomic and financial risk measures from U.S. and Europe. We argue that if these factors can explain the current and future credit markets' spillovers, these can be interpreted as the drivers of such spillovers in Granger causality sense. The results of determinants of aggregate and net directional credit spillover are shown in table 4 and 5, respectively. We estimate four different models for the aggregate spillover as a robustness check and to examine the significance of different impacts. In model 1, we see that US interest rates movements and stock markets volatility explains around $18.1 \%$ variations in the aggregate credit spillovers among European markets. This is expected because GFC originating from US significantly impacted the economies around the world and more defaults occurred during that specific sub-period. In model 2, we add business conditions index and the G-10 economic surprise index. It is worth noting that improvements in business conditions decrease the credit market spillovers whereas G-10 economic surprise index has no significant impact. Both news surprise index and uncertainty indices of Scotti (2016) for euro region significantly increase the spillovers, as shown

in model 3. The currency factor is only significant at $10 \%$ level in model 4 . Overall, the considered factors significantly explain (about 27\%) the credit markets' aggregate spillovers in Europe.

We further investigate the determinants of net directional spillovers of individual European countries. We therefore regress the 12-day-ahead net directional spillover indices on selected 
determinants and the results are reported in Table 5. The adjusted $\mathrm{R}^{2}$ values, ranging from highest $48.2 \%$ for the Austrian credit market to the lowest 5.6\% for the French credit market, show variation across countries. The coefficients of determinants of the net directional spillovers are significantly for most markets, however, signs show heterogeneity across individual spillovers.

\section{[Insert Table $4 \& 5$ here]}

\section{Conclusions}

The occurrence of the sovereign debt crisis in the Euro area in late 2009 raised the concern of the contagion effect and volatility shocks transmission. In this paper, we elucidate the connectedness between SCDS in 13 European credit markets including Eurozone markets, peripheral countries, and central European countries and two north Scandinavian countries. Our main motivation is to explore the causality relationships over the entirety of the European region, hence reveal the geographical partitions of causal connections and spillovers between European SCDS markets. Doing so, we propose a novel approach combining the Granger causality tests and copula method within a SVAR process. We extended this framework by checking the relevance of some key determinants governing the spillovers behavior over time among the SCDS markets. We implement the rolling window spillovers analysis.

Broadly speaking, we come to the following conclusions. First, our copula-Granger causality reveals a significant causal flow of SCDS spreads from one market to another European market. Specifically, Sweden was identified as an exogenous source of spillover and affects the UK, Austria, Denmark, Netherlands and Norway but does not receive inflows from the other markets. 
Contrariwise, Denmark is a prime receiver in contemporaneous time from other markets, followed by UK and Norway. The economic inference of the revealed empirical evidence refers mainly to the attribution of spillovers not only to second-moment effects in financial markets but to the holistic outcome of the combination of correlation, volatility interrelationships as well as tail-related contagion traits that altogether comprise co-movements across financial markets. Hence, we detected lead-lag linkages among markets caused by higher moments. Our approach measures a general time-static dependence structure including lags, in a way that we could infer on directional predictability between the investigated market returns. E.g., the finding that Sweden appears to affect the UK, Austria, Denmark, Netherlands and Norway relates to a discovered unidirectional relationship as opposed to a two-way link detected in other cases.

Second, the rolling window spillovers framework allowed us to measure the spillovers intensities among the credit markets. We showed that, for a 12-day ahead spillover, the highest for Italy and France. Denmark is the highest spillover receiver while Sweden receives the lowest volatility spillovers effects. Additionally, we found that the overall spillover index (SOI) among the SCDS markets is relatively high $(84.9 \%)$. Furthermore, we unveil that the credit markets spillovers strengthened during GFC and ESDC periods, with strong jumps with the start of the financial crisis and persisted higher during the crisis periods and significantly decrease post-ESDC period and remains lower towards the end of our sample period.

Third, we checked the relevance of some global risk factors as key drivers of the spillovers among the European SCDSs. Our results point out that the US interest rates and the US exchange rate against the Euro are explaining a large part of the SCDS market volatility spillovers. Moreover, we show that the enhancements in the US business conditions shrinks the credit market spillovers while the G-10 economic surprise index has no significant effect. Conversely, 
a substantial positive effect of the news surprise index and uncertainty index for the Euro region has been evidenced.

We deem that these findings are interesting. They are useful for building asset-pricing models and they are of great importance for international portfolio managers envisaging the diversification gains form their SCDS portfolios. Our proposed framework of the rolling window volatility spillovers allows us to gauge the progress of the emerging and existing crisis among the European credit markets that may offer a contemporary information which countries can be identified as the most contagious in a given system. Furthermore, from a financial stability perspective in the Eurozone, understanding in a very convincing way the main global risk factors deriving the causality flows among the European SCDS markets is very useful for policy makers and credit market regulators when designing their economic policies. More importantly, from an operational risk management, our findings may help banks, financial institutions, hedge funds and other international investors to assess risk and to compute in a more accurate manner their capital charge requirements.

\section{Acknowledgements}

The authors wish to thank the Editor-in-Chief Professor M. P. Taylor and two anonymous referees for their valuable inputs. C. Aloui would like to acknowledge Business, Society \& Environment (BSE) Research Lab, Prince Sultan University, Saudi Arabia for their support.

\section{References}

Ait-Sahalia, Y., R.J.A., Laeven, L., Pelizzon (2014). Mutual excitation in Eurozone sovereign CDS. Journal of Econometrics 183, 151-167

Alter, A., A., Beyer (2014). The dynamics of spillover effects during the European sovereign debt turmoil. Journal of Banking and Finance 42, 134-153

Arnold, A., Y. Liu, and N. Abe. (2007). Temporal causal modeling with graphical granger methods. Discovery and Data Mining, KDD '07, New York, 66-75

Aruoba, S. B., Diebold, F. X., \& Scotti, C. (2009). Real-time measurement of business conditions. Journal of Business \& Economic Statistics, 27(4), 417-427. 
Atil, A., M., Bradford, A., El Marzougui, A., Lahiani (2016). Conditional dependence of US and EU sovereign CDS: A time-varying copula-based estimation. Finance Research Letters $19,42-53$

Bahadori, T. and Liu, Y. (2013). An examination of large-scale Granger causality inference. In: SIAM Conference on Data Mining, ISBN 978-1-61197-262-7

Billio, M., M., Getmansky, A.W., Lo, L., Pelizzon (2012). Econometric measures of connectedness and systemic risk in the finance and insurance sectors. Journal of Financial Economics 104, 539-559

Blommestein, H., S., Eijiffinger, Z., Qian (2016). Regime-dependent determinants of Euro area sovereign CDS spreads. Journal of Financial Stability 22, 10-21

Bostanci, G., K., Yilmaz (2015). How Connected is the Global Sovereign Credit Risk Network? Working paper Koç University, Tusiad Economic Research Forum

Broto, C., G., Perez-Quiros (2015). Disentangling contagion among sovereign CDS spreads during the European debt crisis. Journal of Empirical Finance 32, 165-179

Calice, G., J., Chen, J., Willams (2013). Liquidity spillovers in sovereign bond and CDS markets: an analysis of the Eurozone sovereign debt crisis. Journal of Economic behavior and Organization 85, 122-143

De Bruyckere, V., M., Gerhardt, G., Schepens, R.V. Vennet (2013). Bank sovereign risk spillovers in the European debt crisis. Journal of Banking and Finance 12, 4793-4809

Diebold, F.X. and Yilmaz, K. (2014), On the Network Topology of Variance Decompositions: Measuring the Connectedness of Financial Firms. Journal of Econometrics 182, 119-134.

Fabozzi, F.J., R., Giaometti, N., Tsuchida (2016). Factor decomposition of the Eurozone sovereign CDS spreads. Journal of International Money and Finance 65, 1-23

Flood, R. P., \& Hodrick, R. J. (1986). Real aspects of exchange rate regime choice with collapsing fixed rates. Journal of International Economics, 21(3-4), 215-232.

Galariotis, E., P., Panagiota, S., Spyrou (2016). Sovereign CDS spread determinants and spillover effects during financial crisis: A panel VAR approach. Journal of Financial Stability $26,62-77$

Hu, M., H., Liang (2014). A copula approach to assessing Granger causality. NeuroImage, $100,125-134$

Kalbaska, A., M., Gatkowski (2012). Eurozone sovereign contagion: evidence from the CDS market (2005-2010). Journal of Economic Behavior and Organization 85, 657-683

Kitwiwattanachai, C., (2015). Learning Network Structure of Financial Institutions from CDS Data. Working paper University of Connecticut, School of Business, USA

Kocsis, Z., Z. Monostori, (2016). The role of country-specific fundamentals in sovereign CDS spreads Eastern European experiences. Emerging Markets Review 27. 140-168.

Koop, G., Pesaran, M. H., \& Potter, S. M. (1996). Impulse response analysis in nonlinear multivariate models. Journal of Econometrics, 74(1), 119-147.

Leon, C., K., Leiton, J., Perez (2014). Extracting the sovereigns' CDS market hierarchy: A correlation-filtering approach. Physica A: Statistical Mechanics and its Applications 145, 407-420

Liu, H., J.D., Lafferty, L.A., Wasserman (2009). The nonparanormal: Semiparametric estimation of high dimensional undirected graphs. Journal of Machine Learning Research 10, 22952328 . 
Longstaff, Francis A., Jun Pan, Lasse H. Pedersen, and Kenneth J. Singleton. (2011). "How Sovereign Is Sovereign Credit Risk?" American Economic Journal: Macroeconomics 3(2): $75-103$.

Lutkepohl, H. (2015). New Introduction to Multiple Time Series Analysis. Springer

Meinshausen, N., B., Yu (2009). Lasso-type recovery of sparse representations for highdimensional data. Annals of Statistics 37, 246-270

Newey, W. K., \& West, K. D. (1987). A simple, positive semi-definite, heteroskedasticity and autocorrelation consistent covariance matrix. Econometrica, 55, 703-708.

Pesaran, H. H., \& Shin, Y. (1998). Generalized impulse response analysis in linear multivariate models. Economics Letters, 58(1), 17-29.

Scotti, C. (2016). Surprise and uncertainty indexes: Real-time aggregation of real-activity macrosurprises. Journal of Monetary Economics, 82, 1-19.

Shahzad, S. J. H., Nor, S. M., Ferrer, R., \& Hammoudeh, S. (2017). Asymmetric determinants of CDS spreads: US industry-level evidence through the NARDL approach. Economic Modelling, 60, 211-230.

Song, S., Bickel, P. J. (2011). Large vector auto regressions, Discussion Paper arXiv:1106.3915v1, University of California, Berkeley.

Wasserman. L (2005). All of Nonparametric Statistics: a Concise Course in Nonparametric Statistcal Inference. New York, Springer-Verlag

Zhao, P., B., Yu (2006). On Model Selection Consistency of Lasso. Journal of Machine Learning Research 7, 2541-2563 
Figure 1: Box plots for European sovereign credit default swap spreads.

a). Full sample period

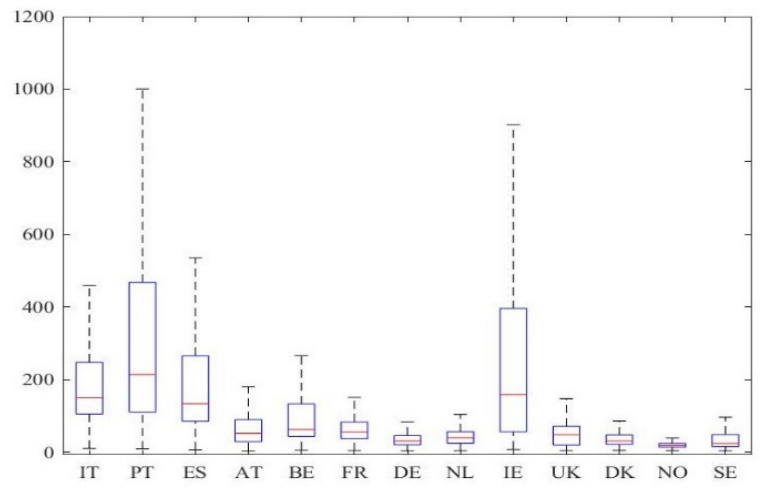

c). ESDC sub-sample period

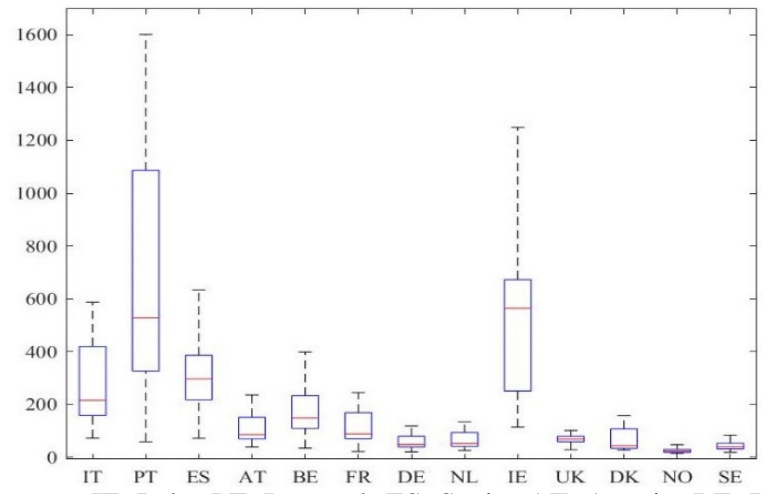

b). GFC sub-sample period

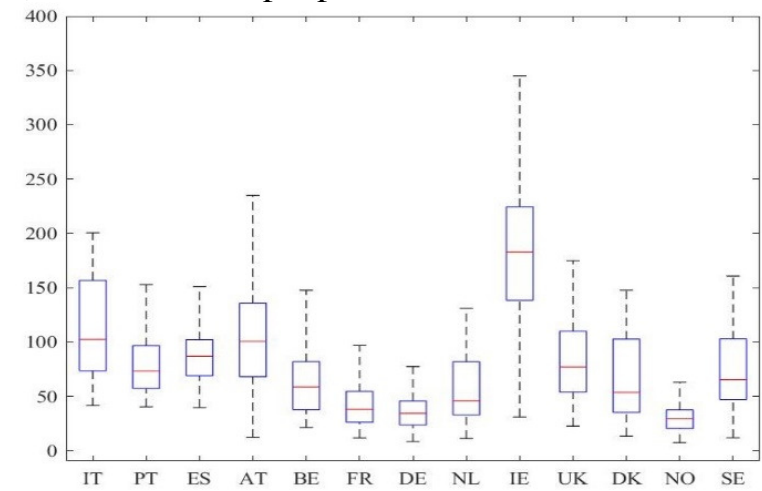

Post-ESDC sub-sample period

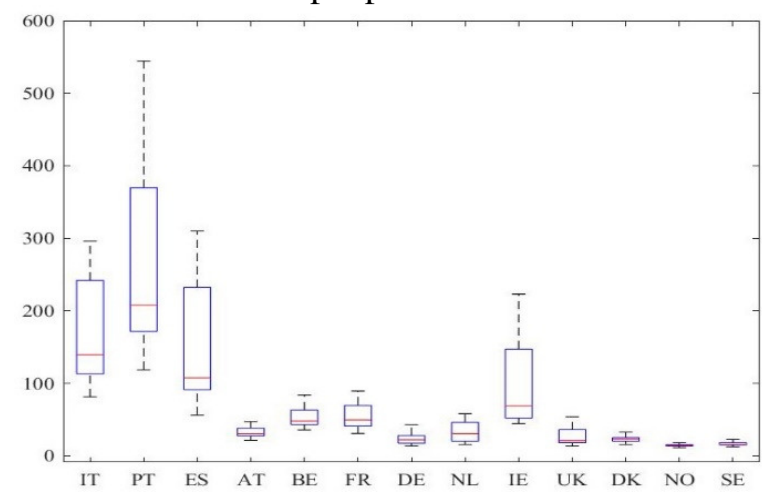

Notes: IT=Italy; PT=Portugal; ES=Spain; AT=Austria; BE=Belgium; FR=France; DE=Germany; NL=Netherlands; IE=Ireland; $\mathrm{UK}=\mathrm{UK}$; DK=Denmark; NO=Norway; $\mathrm{SE}=$ Sweden. 
Figure 2: Correlation heat maps

a). Full sample period

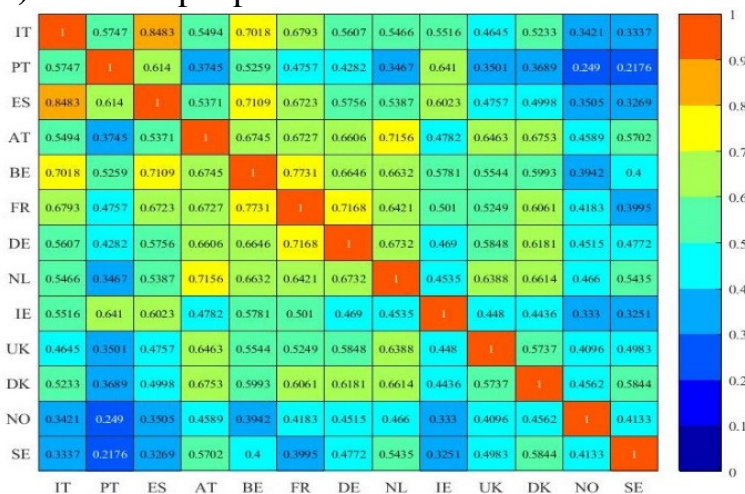

c). ESDC sub-sample period

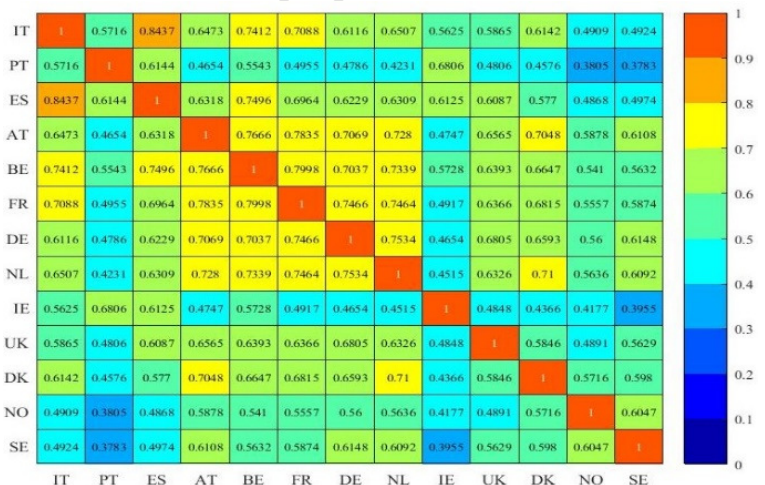

b). GFC sub-sample period

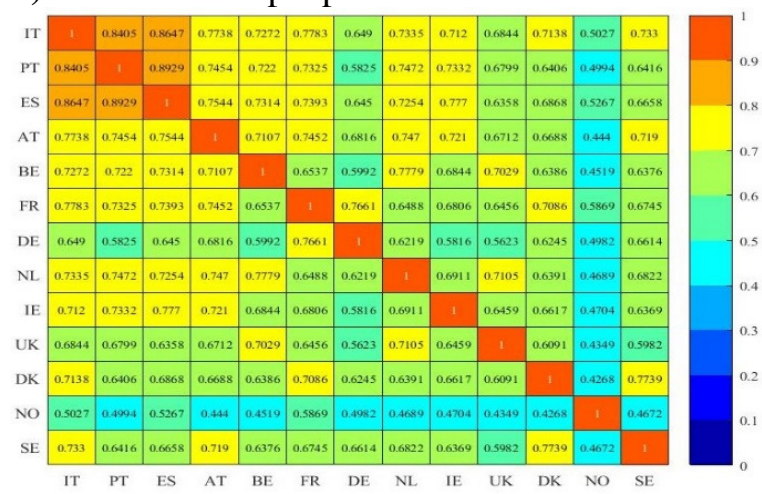

d). Post-ESDC sub-sample period

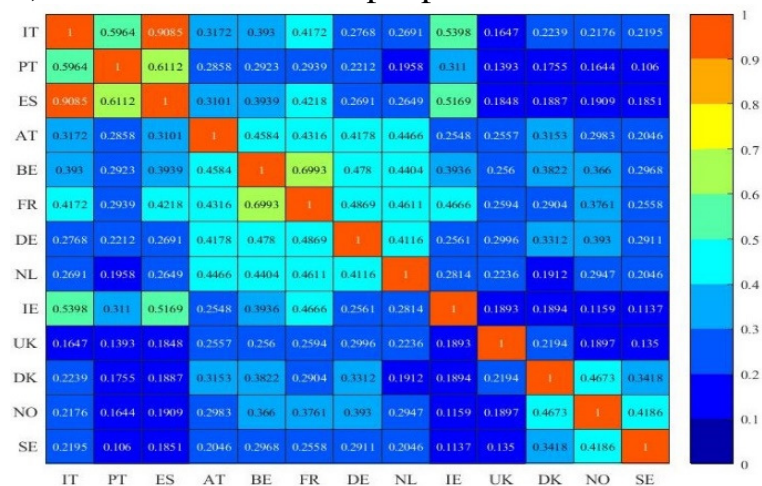

Notes: The figures illustrate the correlations between pairs of SCDS markets obtained by the Kendall tau metric. From the top to the bottom, the matrices correspond to the full sample, GFC, ESDC and post crisis periods, as defined. IT=Italy; PT=Portugal; $\mathrm{ES}=$ Spain; AT=Austria; $\mathrm{BE}=$ Belgium; $\mathrm{FR}=$ France; $\mathrm{DE}=$ Germany; NL=Netherlands; IE=Ireland; UK=UK; DK=Denmark; $\mathrm{NO}=$ Norway; $\mathrm{SE}=$ Sweden. 
Figure 3: Causal flow patterns among changes of SCDS - Hu and Liang (2014)

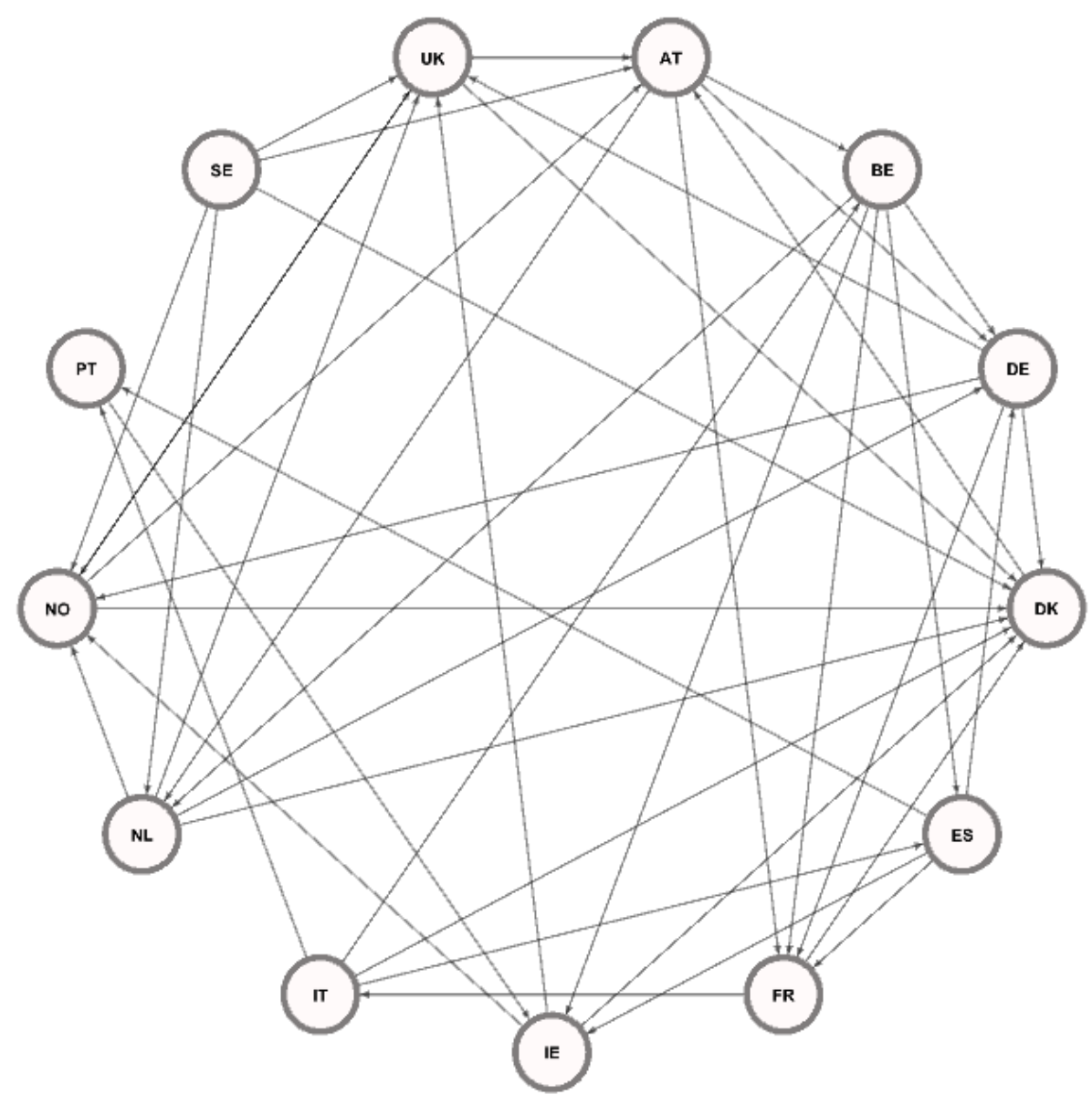

Note: This figure shows the contemporaneous causal flow patterns among CDS changes. The analysis is conducted using a Copula Granger causality approach by Hu and Liang (2014) with the resulting graph at the conventional 5\% significance level.

Figure 4: Aggregate spillover index of European credit markets 


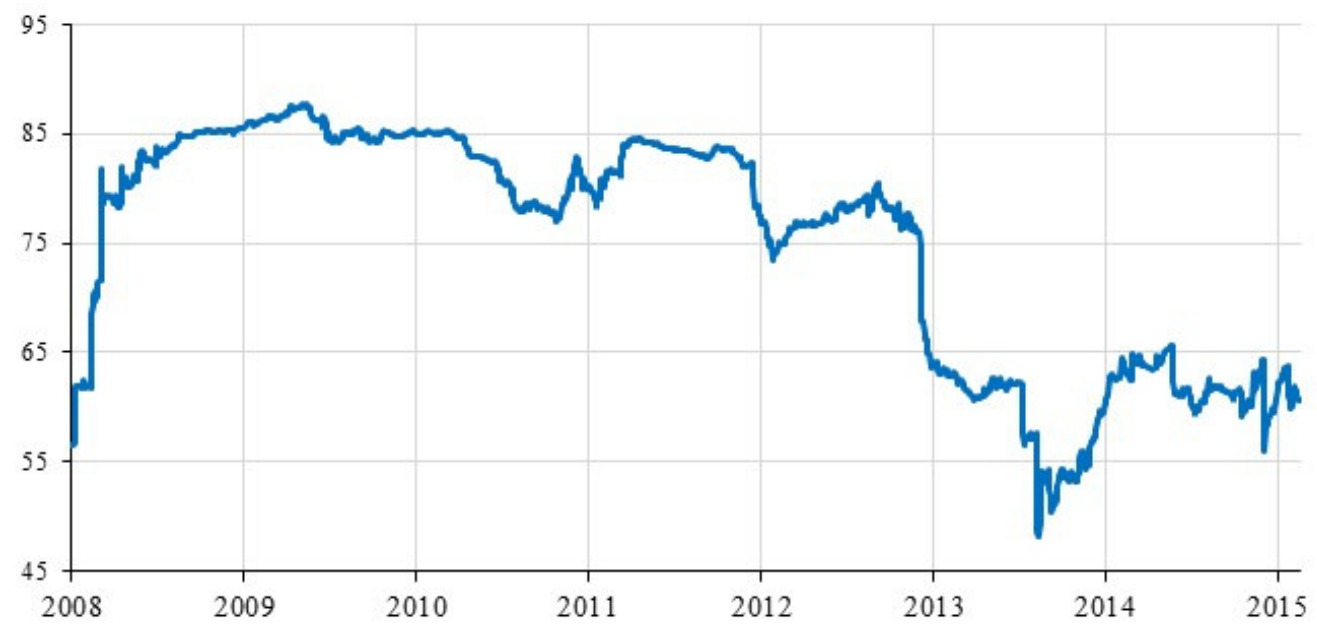

Notes: This figure plots the aggregate spillover index of the European credit markets, which is the sum of all recursive variance decomposition contributions each day at horizons of 12 days. The initial sample period is from November 13, 2007, to August 18,2008 , a total of 200 daily observations and the variance decompositions are estimated recursively each day with an expanding sample until the end of our sample period which is October 6, 2015. 
Table 1: Full sample spillover analysis

\begin{tabular}{|c|c|c|c|c|c|c|c|c|c|c|c|c|c|c|}
\hline & \multicolumn{13}{|c|}{ From $(j)$} & \multirow{2}{*}{$\begin{array}{l}\text { Contribution } \\
\text { from others }\end{array}$} \\
\hline To $(i)$ & IT & PT & ES & AT & $\mathrm{BE}$ & FR & $\mathrm{DE}$ & NL & IE & UK & DK & NO & SE & \\
\hline IT & 20.0 & 3.5 & 9.2 & 0.1 & 0.1 & 27.1 & 3.2 & 0.3 & 0.7 & 0.0 & 0.0 & 0.2 & 0.2 & 44.4 \\
\hline PT & 11.1 & 7.4 & 56.6 & 0.0 & 0.5 & 7.3 & 1.9 & 0.1 & 0.3 & 0.1 & 1.0 & 0.6 & 0.1 & 79.7 \\
\hline ES & 13.4 & 0.7 & 38.9 & 0.0 & 63.1 & 10.3 & 2.5 & 0.2 & 0.5 & 0.0 & 0.0 & 0.1 & 0.1 & 90.8 \\
\hline AT & 12.9 & 0.8 & 9.8 & 0.4 & 0.1 & 9.4 & 1.9 & 0.2 & 0.8 & 0.0 & 63.8 & 0.0 & 0.6 & 100.1 \\
\hline $\mathrm{BE}$ & 50.5 & 1.0 & 0.7 & 0.1 & 0.3 & 4.6 & 7.8 & 0.7 & 1.1 & 0.0 & 0.1 & 0.1 & 0.3 & 66.9 \\
\hline FR & 6.0 & 1.3 & 2.3 & 0.1 & 0.3 & 1.7 & 24.8 & 0.1 & 0.8 & 0.0 & 0.4 & 0.1 & 0.0 & 36.1 \\
\hline $\mathrm{DE}$ & 36.2 & 0.6 & 3.4 & 52.2 & 4.2 & 15.2 & 0.1 & 2.5 & 0.4 & 0.0 & 0.0 & 0.1 & 0.8 & 115.5 \\
\hline $\mathrm{NL}$ & 21.1 & 0.4 & 2.2 & 0.7 & 8.9 & 14.8 & 3.0 & 43.8 & 1.0 & 0.0 & 0.1 & 0.2 & 3.8 & 56.2 \\
\hline IE & 13.1 & 34.0 & 8.7 & 1.6 & 19.4 & 5.4 & 1.1 & 0.1 & 0.0 & 0.0 & 0.2 & 3.1 & 1.1 & 87.8 \\
\hline UK & 11.0 & 0.3 & 3.6 & 0.3 & 4.3 & 7.7 & 0.0 & 6.1 & 60.7 & 3.1 & 6.4 & 50.8 & 6.2 & 157.3 \\
\hline DK & 92.9 & 0.8 & 4.3 & 0.1 & 1.4 & 37.5 & 8.5 & 0.3 & 4.5 & 1.2 & 0.6 & 0.2 & 9.5 & 161.0 \\
\hline $\mathrm{NO}$ & 4.5 & 0.2 & 1.8 & 0.1 & 5.8 & 3.7 & 0.5 & 2.5 & 7.5 & 71.1 & 0.3 & 5.3 & 3.7 & 101.7 \\
\hline SE & 0.4 & 0.0 & 0.7 & 0.1 & 4.3 & 0.4 & 0.1 & 0.0 & 0.2 & 0.0 & 0.0 & 0.0 & 93.8 & 6.3 \\
\hline \begin{tabular}{|l|} 
Contribution \\
to others
\end{tabular} & 273.0 & 43.5 & 103.2 & 55.2 & 112.5 & 143.4 & 55.2 & 12.9 & 78.4 & 72.5 & 72.2 & 55.5 & 26.2 & SOI $=84.9$ \\
\hline
\end{tabular}

Note: This table presents the percentage of contribution to the forecast error variance of variable $i$ coming from shocks to variable $j$ using all the sample period. The column named "Contribution from others" are the sum of the percentage of contribution of each variable except the own variable. Similarly, the row named "Contribution to others" are the sum of the percentage of contribution of each variable except the own variable. Moreover, the total return spillover index - SOI (expressed as a percentage) appears in the lower right corner of the table. This index is calculated as the sum of all the contributions in the "Contribution to others" column (or the sum of all the "Contribution to others" row) divided by the number of variables included in the model. The variance decomposition is based on the directed graph on innovations given in Figure 3 
Table 2: Summary statistics of aggregate daily spillover and individual net spillovers of European credit market

\begin{tabular}{|l|r|r|r|r|r|r|c|}
\hline & \multicolumn{1}{l}{ Mean } & \multicolumn{1}{l}{ Std. Dev. } & \multicolumn{1}{l}{ Skew } & \multicolumn{1}{l}{ Kurt } & \multicolumn{1}{l}{ Min. } & \multicolumn{1}{l}{ Max. } & ADF test p-values \\
\hline Aggregate & 75.040 & 10.592 & -0.651 & 1.894 & 48.207 & 87.712 & $<0.010$ \\
\hline Italy & $\mathbf{0 . 9 8 6}$ & 0.915 & -0.775 & 3.465 & -1.679 & 3.335 & $<0.010$ \\
\hline Portugal & -0.437 & 1.315 & -0.842 & 2.819 & -3.975 & 1.708 & $<0.010$ \\
\hline Spain & $\mathbf{1 . 2 8 6}$ & 0.601 & 1.201 & 5.787 & 0.062 & 3.806 & $<0.010$ \\
\hline Austria & $\mathbf{0 . 4 9 6}$ & 0.936 & 0.210 & 2.224 & -1.727 & 3.516 & $<0.050$ \\
\hline Belgium & $\mathbf{0 . 6 5 8}$ & 1.061 & -0.489 & 3.191 & -2.747 & 2.619 & $<0.010$ \\
\hline France & $\mathbf{0 . 6 3 9}$ & 0.572 & -0.407 & 2.508 & -0.832 & 1.954 & $<0.010$ \\
\hline Germany & -0.121 & 0.896 & -0.279 & 1.960 & -2.257 & 1.697 & $<0.010$ \\
\hline Netherlands & $\mathbf{0 . 2 5 5}$ & 0.650 & -0.216 & 2.646 & -1.179 & 1.885 & $<0.050$ \\
\hline Ireland & -0.346 & 0.982 & 0.275 & 1.883 & -2.084 & 2.370 & $<0.010$ \\
\hline UK & -0.410 & 0.904 & -0.277 & 2.669 & -3.253 & 1.354 & $<0.100$ \\
\hline Denmark & -0.362 & 0.800 & 0.354 & 2.329 & -2.435 & 1.639 & $<0.100$ \\
\hline Norway & -1.753 & 1.129 & -0.315 & 2.098 & -4.174 & 0.035 & $<0.010$ \\
\hline Sweden & -0.891 & 0.763 & 0.112 & 3.232 & -2.696 & 2.472 & $<0.010$ \\
\hline
\end{tabular}

Notes: This table presents summary statistics for daily spillover indices from August 18, 2008, to October 6, 2015. Number of observations is 1,859. As defined in Equation (10), the aggregate spillover index is the sum of all recursive variance decomposition contributions among considered European credit markets. As defined in Equation (13), the individual net spillover index is the difference between recursive variance decomposition contribution from and to a specific credit market. Positive (in bold) average values indicate that the country's credit markets is transmitter in net terms and negative values indicate otherwise. The ADF test is the augmented Dickey and Fuller $(1979,1981)$ unit root test for the intercept and trend case. 
Table 3: Daily correlations among the aggregate spillover index and determinants

\begin{tabular}{|l|r|r|r|r|r|r|r|l|}
\hline & $\begin{array}{l}\text { Aggregate } \\
\text { spillover }\end{array}$ & Short & Term & VIX & ADS & $\Delta$ CESG10 & SUR & UNC \\
\hline Short & 0.0103 & & & & & & & \\
\hline Term & $0.2378^{* * * *}$ & 0.0141 & & & & & & \\
\hline VIX & $0.3916^{* * *}$ & $0.1351^{* * *}$ & $0.2088^{* * * *}$ & & & & & \\
\hline ADS & $-0.1059^{* * *}$ & $-0.3712^{* * *}$ & $-0.0387^{*}$ & $-0.6808^{* * *}$ & & & & \\
\hline$\Delta$ CESG10 & 0.0188 & 0.0146 & 0.0280 & 0.0001 & 0.0225 & & & \\
\hline SUR & $0.2568^{* * *}$ & $0.0456^{* *}$ & $0.1724^{* * *}$ & $0.2607^{* * *}$ & $-0.2357^{* * *}$ & $0.0641^{*}$ & & \\
\hline UNC & $0.3132^{* * *}$ & $0.1361^{* * *}$ & $0.1492^{* * *}$ & $0.6428^{* * *}$ & $-0.6830^{* * *}$ & $0.0423^{*}$ & $-0.3041^{* * *}$ & \\
\hline$\Delta \mathrm{FX}$ & 0.0178 & $0.0392^{*}$ & 0.0118 & 0.0332 & 0.0013 & $0.0457^{* *}$ & -0.0173 & -0.0050 \\
\hline
\end{tabular}

Notes: This table reports daily correlations between the 12-day-ahead aggregate spillover index and the determinants. As defined in Equation (10), the aggregate spillover index is the sum of all recursive variance decomposition contributions among 13 European credit markets. SHORT is the U.S. short rate (one-month treasury rate). TERM is term spread defined as the difference between the 10-year and three-month Treasury yields. VIX is the implied volatility of the US stock market. ADS is the Aruoba et al. (2009) business condition index. $\triangle$ CESG10 is the change of Citigroup's economic surprise index for the G10. SUR and UNC are the Scotti (2016) Surprise and uncertainty indexes for Europe. $\Delta \mathrm{FX}$ is the change of the Euro to US dollar exchange rate. $*, * *, * * *$ denote significance at $10 \%, 5 \%$, and $1 \%$, respectively 
Table 4: Determinants of aggregate spillovers among European credit markets

\begin{tabular}{|l|r|r|r|r|}
\hline & Model 1 & Model 2 & Model 3 & \multicolumn{1}{c|}{ Model 4 } \\
\hline Short & $3.839^{* * *}$ & 1.103 & $2.880^{* * *}$ & $3.000^{* * *}$ \\
\hline Term & $(2.934)$ & $(0.795)$ & $(2.134)$ & $(2.222)$ \\
\hline & $2.786^{* * *}$ & $2.293^{* * *}$ & $1.646^{* * * *}$ & $1.632^{* * * *}$ \\
\hline VIX & $(7.561)$ & $(6.289)$ & $(4.622)$ & $(4.584)$ \\
\hline & $0.358^{* * * *}$ & $0.543^{* * *}$ & $0.454^{* * *}$ & $0.457^{* * * *}$ \\
\hline ADS & $(16.903)$ & $(18.866)$ & $(15.676)$ & $(15.758)$ \\
\hline & & $-3.077^{* * *}$ & $-4.743^{* * *}$ & $-4.772^{* * * *}$ \\
\hline$\Delta$ CESG10 & & $(-9.255)$ & $(-13.147)$ & $(-13.221)$ \\
\hline & & 0.097 & $0.172^{* * *}$ & $0.178^{* * * *}$ \\
\hline SUR & & $(1.396)$ & $(2.553)$ & $(2.630)$ \\
\hline & & & $4.123^{* * *}$ & $4.105^{* * *}$ \\
\hline UNC & & & $(6.997)$ & $(6.969)$ \\
\hline & & & $5.779^{* * * *}$ & $5.786^{* * *}$ \\
\hline$\Delta$ FX & & & $(8.509)$ & $(8.522)$ \\
\hline & & & & $4.217^{*}$ \\
\hline Adj. R & & & & $(1.750)$ \\
\hline
\end{tabular}

Notes: This table reports the results of the regressions using 1859 daily observations: dependent variable is the daily 12 -stepahead aggregate spillover index among 13 European credit markets, which is the sum of the shares of recursive forecast error variances. SHORT is the U.S. short rate (one-month treasury rate). TERM is term spread defined as the difference between the 10-year and three-month Treasury yields. VIX is the implied volatility of the US stock market. ADS is the Aruoba et al. (2009) business condition index. $\triangle$ CESG10 is the change of Citigroup's economic surprise index for the G10. SUR and UNC are the Scotti (2016) Surprise and uncertainty indexes for Europe. $\triangle \mathrm{FX}$ is the change of the Euro to US dollar exchange rate. The robust t-statistics (using Newey and West (1987) HAC) are reported in parentheses. Intercepts are not reported to save space.

$*, * *, * * *$ denote significance at $10 \%, 5 \%$, and $1 \%$, respectively 
Table 5: Determinants of individual net spillovers of European credit markets

\begin{tabular}{|c|c|c|c|c|c|c|c|c|c|}
\hline & Short & Term & VIX & ADS & $\Delta$ CESG10 & SUR & UNC & $\Delta \mathrm{FX}$ & Adj. $\mathrm{R}^{2}$ \\
\hline \multirow[t]{2}{*}{ Italy } & $-2.411^{\text {**** }}$ & $0.271^{\text {****** }}$ & $0.016^{\text {***** }}$ & $-0.272^{\text {**** }}$ & 0.000 & $0.123^{\text {*** }}$ & $-0.776^{\text {***** }}$ & -1.681 & 0.256 \\
\hline & $(-20.432)$ & $(8.699)$ & $(6.477)$ & $(-8.638)$ & $(0.039)$ & $(2.392)$ & $(-13.086)$ & $(-0.816)$ & \\
\hline \multirow[t]{2}{*}{ Portugal } & $-1.330^{* * *}$ & $1.172^{\text {**** }}$ & $0.022^{\text {**** }}$ & $-0.585^{* * *}$ & 0.005 & 0.095 & $-1.087^{\text {**** }}$ & -0.953 & 0.434 \\
\hline & $(-8.977)$ & (30.010) & $(6.848)$ & $(-14.778)$ & $(0.712)$ & $(1.472)$ & $(-14.585)$ & $(-0.368)$ & \\
\hline \multirow[t]{2}{*}{ Spain } & $1.236^{* * *}$ & $-0.081^{* * * *}$ & 0.000 & $-0.198^{* * *}$ & $-0.006^{*}$ & $-0.123^{* * *}$ & 0.046 & -0.931 & 0.360 \\
\hline & $(17.147)$ & $(-4.239)$ & $(0.172)$ & $(-10.289)$ & $(-1.715)$ & $(-3.912)$ & $(1.270)$ & $(-0.740)$ & \\
\hline \multirow[t]{2}{*}{ Austria } & -0.144 & $-0.288^{* * * * *}$ & $-0.028^{* * * * *}$ & $-0.354^{* * * *}$ & $0.009^{*}$ & 0.039 & $1.189^{\text {**** }}$ & 2.515 & 0.482 \\
\hline & $(-1.427)$ & $(-10.862)$ & $(-12.994)$ & $(-13.138)$ & (1.818) & $(0.880)$ & $(23.483)$ & (1.431) & \\
\hline \multirow[t]{2}{*}{ Belgium } & $-1.161^{* * * *}$ & $-0.596^{* * *}$ & $-0.022^{* * *}$ & $0.441^{* * * *}$ & $0.014^{* * *}$ & $-0.239^{* * *}$ & $0.324^{* * * *}$ & 0.257 & 0.462 \\
\hline & $(-9.960)$ & $(-19.402)$ & $(-8.626)$ & (14.148) & $(2.330)$ & $(-4.691)$ & (5.523) & $(0.127)$ & \\
\hline \multirow[t]{2}{*}{ France } & -0.112 & $-0.152^{* * *}$ & $-0.006^{* * * *}$ & 0.032 & -0.001 & $-0.069^{*}$ & -0.003 & 0.405 & 0.056 \\
\hline & $(-1.351)$ & $(-6.923)$ & $(-3.442)$ & (1.429) & $(-0.324)$ & $(-1.904)$ & $(-0.070)$ & $(0.280)$ & \\
\hline \multirow[t]{2}{*}{ Germany } & $1.767^{* * *}$ & $-0.479^{* * *}$ & $0.018^{\text {****** }}$ & $0.549^{\text {***** }}$ & 0.000 & -0.048 & 0.038 & -0.178 & 0.288 \\
\hline & (15.624) & $(-16.076)$ & (7.334) & (18.175) & $(0.019)$ & $(-0.972)$ & $(0.671)$ & $(-0.090)$ & \\
\hline \multirow[t]{2}{*}{ Netherlands } & $0.198^{* *}$ & $-0.044^{*}$ & $0.004^{* *}$ & $0.255^{* * * *}$ & $0.010^{* *}$ & $-0.150^{* * *}$ & $0.644^{* * *}$ & $3.273^{* *}$ & 0.132 \\
\hline & (2.193) & $(-1.860)$ & (2.097) & (10.548) & (2.196) & $(-3.798)$ & (14.145) & (2.073) & \\
\hline \multirow[t]{2}{*}{ Ireland } & 0.027 & $0.574^{* * * *}$ & -0.001 & $-0.576^{* * * *}$ & -0.001 & 0.059 & -0.032 & -0.360 & 0.449 \\
\hline & $(0.251)$ & (19.932) & $(-0.317)$ & $(-19.733)$ & $(-0.203)$ & $(1.247)$ & $(-0.583)$ & $(-0.189)$ & \\
\hline \multirow[t]{2}{*}{ UK } & $0.960^{\text {**** }}$ & $-0.179^{* * * *}$ & $0.013^{\text {***** }}$ & $0.348^{\text {***** }}$ & $-0.015^{* * * *}$ & -0.033 & $-0.613^{\text {**** }}$ & -0.130 & 0.276 \\
\hline & $(8.331)$ & $(-5.900)$ & $(5.222)$ & (11.297) & $(-2.686)$ & $(-0.655)$ & $(-10.588)$ & $(-0.064)$ & \\
\hline \multirow[t]{2}{*}{ Denmark } & $1.214^{\text {****}}$ & $-0.296^{* * *}$ & -0.002 & $0.504^{* * *}$ & $0.009^{*}$ & $-0.242^{* * *}$ & $0.846^{* * * *}$ & 1.405 & 0.229 \\
\hline & $(11.527)$ & $(-10.666)$ & $(-0.759)$ & $(17.915)$ & (1.779) & $(-5.268)$ & (15.980) & $(0.765)$ & \\
\hline \multirow[t]{2}{*}{ Norway } & $-1.062^{* * *}$ & $-0.361^{* * *}$ & $-0.031^{\text {**** }}$ & $-0.138^{* * *}$ & $-0.022^{* * * *}$ & $0.341^{\text {**** }}$ & $-0.796^{\text {**** }}$ & $-4.047^{*}$ & 0.412 \\
\hline & $(-8.191)$ & $(-10.564)$ & $(-11.280)$ & $(-3.972)$ & $(-3.365)$ & (6.029) & $(-12.210)$ & $(-1.788)$ & \\
\hline \multirow[t]{2}{*}{ Sweden } & $0.819^{\text {**** }}$ & $0.460^{\text {***** }}$ & $0.016^{\text {***** }}$ & -0.006 & -0.002 & $0.246^{\text {***** }}$ & $0.221^{* * * *}$ & 0.423 & 0.333 \\
\hline & $(8.772)$ & (18.685) & $(8.206)$ & $(-0.223)$ & $(-0.370)$ & $(6.036)$ & (4.699) & $(0.260)$ & \\
\hline
\end{tabular}

Notes: This table reports the results of the regressions using 1859 daily observations: dependent variable are the individual country's net spillover index based on 12-step-ahead forecast. As defined in Equation (13), the individual net spillover index is the difference between recursive variance decomposition contribution from and to a specific credit market. SHORT is the U.S. short rate (one-month treasury rate). TERM is term spread defined as the difference between the 10-year and three-month Treasury yields. VIX is the implied volatility of the US stock market. ADS is the Aruoba et al. (2009) business condition index. $\triangle$ CESG10 is the change of Citigroup's economic surprise index for the G10. SUR and UNC are the Scotti (2016) Surprise and uncertainty indexes for Europe. $\triangle \mathrm{FX}$ is the change of the Euro to US dollar exchange rate. The robust t-statistics (using Newey and West (1987) HAC) are reported in parentheses. Intercepts are not reported to save space.

$*, * *, * *$ denote significance at $10 \%, 5 \%$, and $1 \%$, respectively 